\title{
RECOVERING FROM NATURAL DISASTERS: HELPING MUSEUM EMPLOYEES RETURN TO WORKPLACE NORMALCY
}

\author{
AMANDA BENSON \\ Museology Department, University of Washington, USA
}

\begin{abstract}
This study evaluated how museums help their employees return to workplace normalcy after a natural disaster affects their institution and professional lives, and to address what policies they used to facilitate this transition. The study focused on three key policies: disaster/emergency plans, business continuity plans, and employee assistance programs (EAPs). Recently, the museum field has pushed for their organizations to develop and implement a disaster preparedness plan as a core institutional policy. While museum disaster preparedness plans are effective in encompassing mitigation, response, and recovery actions for artifacts, they rarely include guidelines for how museum employees are regarded during the recovery phase of the disaster plan. Natural disasters create high levels of stress which can affect worker productivity, and can lead to high employee absenteeism and turnover. Business continuity plans and EAPs can offer a means to address this thesis, as employees are considered a mission-critical resource. A questionnaire was sent to 80 midsize, California museums in the Los Angeles, San Diego, and San Francisco Bay areas. The majority of museums (79\%) indicated that they had a disaster preparedness plan in place, but not a business continuity plan (14\%) or an employee assistance program (30\%). Results concluded that museums are not utilizing these policies to help employees return to workplace normalcy.
\end{abstract}

Keywords: disaster planning, business continuity, emergency management, employee assistance program, museology, museum studies.

\section{INTRODUCTION}

Emergency and disaster planning documents published by leading organizations in the museum field, such as the American Alliance of Museums (AAM), International Council of Museums (ICOM), and the Getty Conservation Institute focus disaster planning efforts to protect the artifacts museums house; however, there is little focus and mention on how museums address the well-being of their employees after a natural disaster affects their institution. These disaster planning guides mention that the safety of visitors and staff are their top priority; however, what happens beyond their initial safety is rarely discussed [1]-[3].

Business continuity plans are a series of procedures to restore normal operations following a disaster. There is debate about the term itself as it applies to non-profits because non-profits do not view themselves as businesses. However, as natural disasters continue to occur, there is a need to consider business continuity planning, especially since it is considered an "underutilized tool" [4].

Employee assistance programs, also known as EAPs, are employer-sponsored programs designed to alleviate and assist in eliminating a variety of workplace problems. The occurrence of natural disasters in the workplace creates stress within employees, and EAPs are becoming an avenue to help them cope with the stressors of disaster [5]. While the amount of EAP efficacy research is thin, current studies show that EAPs can be beneficial and effective to the employees who choose to use them [6]. 
Awareness of natural disasters occurring is increasing in today's society and the wake of their destruction is known to bring communities together. After the devastation after Hurricane Katrina in 2005, and more recently with Hurricane Sandy in 2012, museums and cultural institutions in the United States started to recognize the need to worry about disaster planning and cultural property protection [7]. According to Ready.gov, the United States Department of Homeland Security's disaster preparedness website [8], natural disasters "affect thousands of people every year." In California, the frequency of a natural disaster is higher than other areas in the United States. According to a study by the Federal Emergency Management Agency (FEMA) [9], Los Angeles County has had 53 natural disasters since 1964 and averages, "a little more than one disaster per year." For these reasons, California was chosen as the geographical location to conduct the study.

The trauma from natural disasters not only impact individuals but also impact communities and organizations. Museums are regarded as keystones of local communities and centers of informal education. Museum staff are a driving force for museums and their missions, thus mission functionality depends on them.

\section{METHODOLOGY}

This study distributed an online questionnaire to ascertain how museums help employees return to workplace normalcy by determining what related policies/documents they have or do not have. The process for the study included the creation of the questionnaire instrument, the selection of organizations, sending out the instrument to potential participants, and then analyzing the data of questionnaire respondents.

\subsection{Instrument creation}

The questionnaire comprised 22 questions (Fig. 1). Fifteen questions were close-ended, using dichotomous and scaled questions with a contingency format. The other seven questions were unstructured and open-ended. Survey questions were created using SurveyMonkey.com using logics when applicable. The questions were informed by a literature review and were intended to fill in the gaps of the known literature.

\subsection{Selection of organizations}

Organizations were selected based on the three following criteria: must be located in either the Los Angeles, San Diego, or San Francisco Bay areas; is a non-profit organization; and has annual budget between $\$ 400,000$ and $\$ 4$ million.

This study aimed to be as representative of the museum field as possible and targeted midsize museums. To ensure a large enough sample could be extrapolated, the budget range of $\$ 400,000$ to $\$ 4$ million was selected. An initial search for museums and similar institutions in the selected areas was done via Wikipedia and then narrowed down by non-profit status and annual operating budget using GuideStar.com. GuideStar.com is a website used to help break down and disseminate information about IRS-registered non-profit organizations. Since GuideStar.com reports institutions who submit Forms 990, all institutions were therefore, non-profit. Once the institutions were selected, a web search was conducted for email contact information of Human Resource Managers, or Directors in lieu of a Human Resource Manager. When an email address could not be found for either position, an email for general information was sent out. 


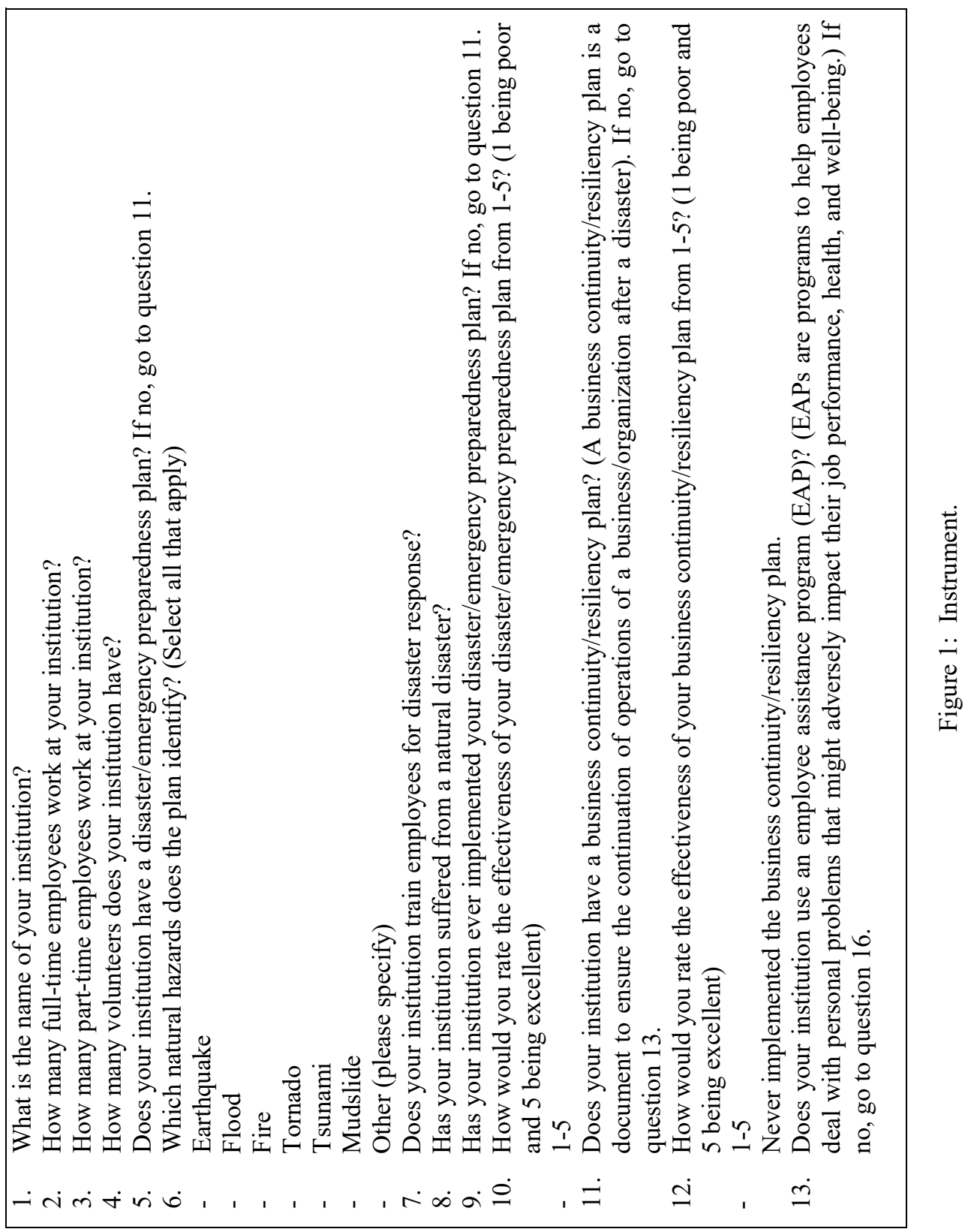




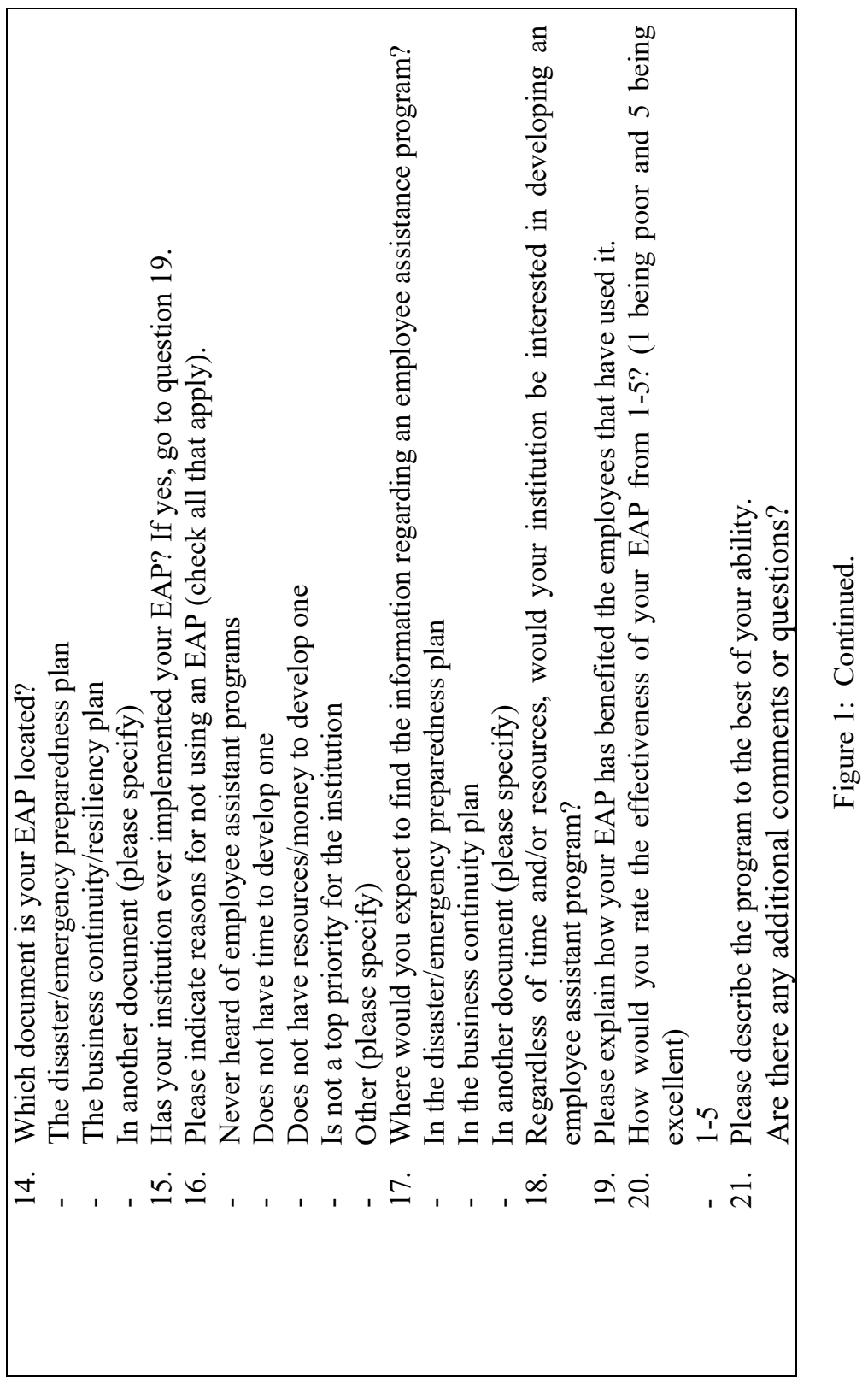




\section{DATA ANALYSIS AND FINDINGS}

Respondents were broken up into one of four categories of museums based on the subject matter of their organization: History, Art, Children's, and Nature/Science. For the purpose of this study, organizations that fell into the "History" category included local history museums, military and aviation museums, and cultural museums. Art museums included cultural art, fine art, textiles, and photographic art while the nature and science group included science museums and botanical gardens. Zoos and aquariums fell outside the required criteria because of their operating budgets.

Of the 80 institutions contacted, a total of 27 responded to the survey either by taking it or replying they could not take it at that time and 24 took the survey, providing a $33 \%$ response rate. The survey was open from February 18, 2016 to March 14, 2016.

The majority of museums that answered were either history (33\%) or art museums $(37 \%)$, making up for over two-thirds of the survey respondents. Children's museums made up for $17 \%$ and $13 \%$ were Nature and Science museums.

\subsection{Institution employee and volunteer size}

The first four questions were used to establish the institutions and to provide groundwork for assessing the number of employees and volunteers each institution had. The majority of both full-time and part-time employees fell between 0 and 10, which illustrates that many institutions operate with a smaller staff size (Table 1). According to Matteson and Ivancevich [10], an organization who wishes to have an on-site EAP program should have a staff size of at least 2000.

Table 1: Full-time employees (FTE), part-time employees (PTE), and volunteers.

\begin{tabular}{|c|c|c|c|}
\hline Respondent & FTE & PTE & Volunteers \\
\hline 1 & 1 & 5 & 50 \\
\hline 2 & 5 & 4 & 8 \\
\hline 3 & 4 & 3 & 10 \\
\hline 4 & 7 & 1 & 4 \\
\hline 5 & 6 & 3 & N/A \\
\hline 6 & 4 & 16 & 50 \\
\hline 7 & 4 & 2 & 10 \\
\hline 8 & 21 & 32 & 50 \\
\hline 9 & 3 & 17 & 40 \\
\hline 10 & 22 & 60 & 100 \\
\hline 11 & 15 & 15 & 10 \\
\hline 12 & 3 & 26 & 10 \\
\hline 13 & 55 & 5 & 200 \\
\hline 14 & 6 & 8 & 10 \\
\hline 15 & 10 & 2 & 30 \\
\hline 16 & 2 & 4 & 20 \\
\hline 17 & 400 & N/A & $\mathrm{N} / \mathrm{A}$ \\
\hline 18 & 18 & 8 & 8 \\
\hline 19 & 4 & 3 & 20 \\
\hline 20 & 15 & 5 & 50 \\
\hline 21 & 7 & 14 & 100 \\
\hline 22 & 0 & 6 & 25 \\
\hline 23 & 25 & 12 & 375 \\
\hline 24 & 4 & 3 & 6 \\
\hline Average/mean & 26.9166667 & 11.04347826 & 53.90909091 \\
\hline Median & 6 & 5 & 22.5 \\
\hline Mode & 4 & 3 & 10 \\
\hline
\end{tabular}


Although the focus of this study is on museum employees, the number of volunteers for each organization provides a different dichotomy to employees. Amongst volunteers, there was a more even spread of data plots, but also had greater numbers than full-time and part-time employees combined. While half of the volunteer base were between 0 and 25 people, the other half represents a volunteer base over 26 people, and often in the triple digits.

\subsection{Disaster planning and implementation}

Questions five and seven were created to affirm the fact that disaster planning for museums is a highly talked about and well-researched field at the moment and that museums are taking disasters and disaster training seriously. $79 \%$ of respondents indicated their institution had a disaster/emergency preparedness plan, and $68 \%$ said they had a training program in place.

For question six, participants were asked to identify the natural hazards in their disaster plan (Table 2). Earthquakes, fires and floods were the top responses, which correlates to FEMA's Disaster Declarations Summary [9]. Flooding was identified as the most frequent hazard, while wildfires and earthquakes were not as common. Since the "Other" category identified man-made and technological hazards, these results are not relevant to the study.

Questions eight, nine, and ten addressed the use of the disaster plan by looking at frequency of use and efficacy of the plans. $17 \%$ of organizations suffered from a natural disaster and $22 \%$ said they have implemented their plan. Implementation of the disaster plan is not directly correlated with natural disasters. Results show that museums are not having to implement their disaster plans, which means that the number of museum employees being affected by a natural disaster are low. For those who did have to implement their disaster plan, they found it somewhat effective $(\mathrm{M}=3.25, \mathrm{SD}=.96)$.

Table 2: Which natural hazards does the disaster plan identify?

\begin{tabular}{|l|l|l|}
\hline Respondent & Hazard type & Type of museum \\
\hline 1 & E, FL, FR & History \\
\hline 2 & E, FL, FR & Nature/science \\
\hline 3 & E, FL, FR & History \\
\hline 4 & Indicated no plan & History \\
\hline 5 & E, FR & Art \\
\hline 6 & E, FL, FR & Art \\
\hline 7 & E, FL, FR, T & History \\
\hline 8 & E, FL, FR, TO, T & Art \\
\hline 9 & E, FL, FR & Art \\
\hline 10 & E, FR & Art \\
\hline 11 & E, FL, FR & Children's \\
\hline 12 & Indicated no plan & Children's \\
\hline 13 & E, FR & Nature/science \\
\hline 14 & Indicated no plan & Art \\
\hline 15 & Indicated no plan & History \\
\hline 16 & E, FL, FR & History \\
\hline 17 & Indicated no plan & History \\
\hline 18 & E, FR & Children's \\
\hline 19 & E, FL, FR & Art \\
\hline 20 & E, F, O & History \\
\hline 21 & E, FR, O & Children's \\
\hline 22 & E, FL, FR, O & History \\
\hline 23 & E, FR & History \\
\hline 24 & Indicated no plan & Art \\
\hline
\end{tabular}

E: Earthquake; FL: Flood; FR: Fire; TO: Tornado; T: Tsunami; O: Other. 


\subsection{Business continuity planning}

Terminology of business continuity planning was defined for the participant in question 11. Twenty-two participants responded to this questions, with $86 \%$ saying they did not have a business continuity plan. Nine of those respondents were history museums, six art, three children's, and one was a nature/science museum. These participants were directed to question 13. Of those who said "yes," (14\%) two were art and one was a nature/science museum. These respondents were taken to question 12 .

For this scale, one indicated a "Poor" rating, five indicated an "Excellent" rating and three was "Neutral." They were also given the option, "Never implemented the business continuity/resiliency plan." One respondent gave it a neutral rating while the other respondents said they never used the plan before.

Because the research on business continuity planning and museums is thin, these questions were asked to establish a baseline for museums with business continuity plans and their thoughts on its efficacy. There is no literature to compare these statistics to, but it does provide an insight about how many museums have business continuity plans. All of the history and children's museums indicated that they did not have a business continuity plan, while some art and nature/science museums do have one in place. As for the efficacy, the results are inconclusive, as the majority of respondents have not implemented their business continuity plan.

\subsection{Employee assistance programs}

Terminology of an employee assistance program was defined for the participant in question 13. Seventy percent $(70 \%)$ indicated that they did not have an EAP, where seven were history museums, seven art, two children's, and one was a nature/science museum. These respondents were directed to question 16 . The $30 \%$ who said they did have an EAP, were three history museums, one art, two children's, and one was a nature/science museum. These respondents were taken to question 14 .

Respondents were asked if their document was in their disaster plan, business continuity plan, or in another document. All replied "In another location" and were asked to specify where the document was located. One respondent said it was provided to them from an outside source, while the others indicated it was in some form of a Human Resources document, such as a handbook or manual. For question 15, of these seven participants, four said that they have had employees use the EAP. One of each of the museum types was represented in the data. The other three respondents skipped the question. These four participants were taken to question 19.

For question 16, participants that indicated that they did not have an EAP were asked to select from a list of reasons for not having one and were told to select all that applied. They also had the option to specify another reason that was not listed (Fig. 2). "Money and resources" (58\%) was the top explanation for not having an EAP. "Not a top priority" (47\%) and "never heard of an EAP" $(41 \%)$ came in as the second and third reasons, respectively. Eleven percent (11\%) specified a different reason for not having an EAP and indicated the institution size was too small.

Question 17 indicated forty-two percent (42\%) thought the EAP would be located in the disaster plan, $21 \%$ believed it would be located in the business continuity plan, and $36 \%$ believed it would be located in another document other than a disaster plan or a business continuity plan. Three of those respondents thought that it would be in an employee handbook or manual, one said it would be its own plan, and the other did not know where it would be located. 


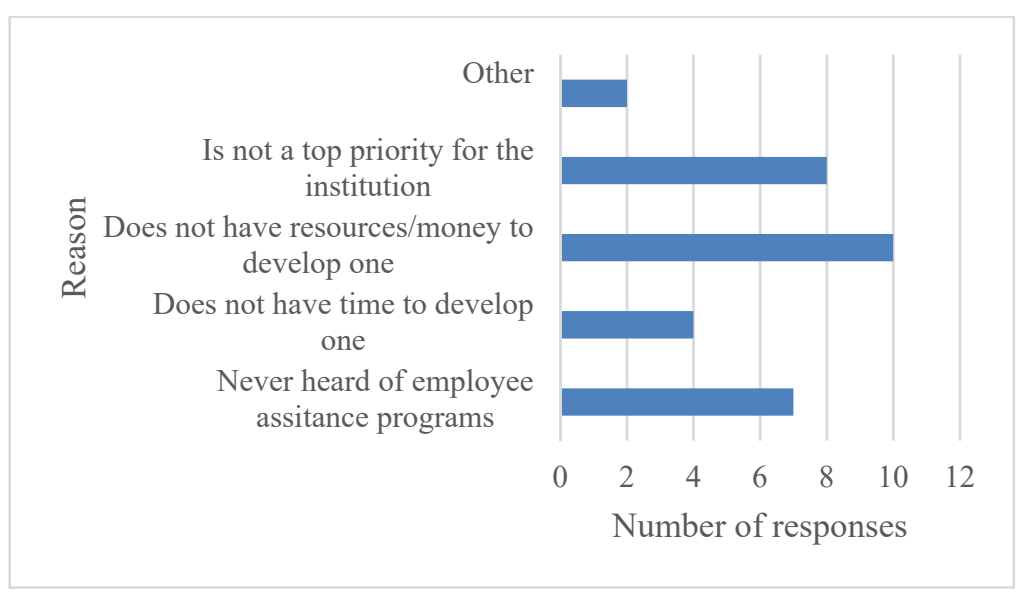

Figure 2: Reasons for not having an EAP.

For question 18 , sixty-two percent (62\%) said they would be interested while $38 \%$ said they were not interested. Of those who said they would be interested, history and art museums had 4 responses each, 2 responses from children's museums, and no responses from nature/science museums.

Going back to those who said their organization had an EAP, question 19 allowed participants who said they have an EAP to expand on the benefits their EAP brought to their employees and organization. Responses were coded and keywords were found amongst responses. Half of these respondents addressed the issue of confidentiality for the employee(s) who used the EAP. Three quarters indicated that their employees used their EAP before, and half mentioned that their EAP benefitted their employee individually. For the scale in question 20, one indicated a "Poor" rating, five indicated an "Excellent" rating and three was "Neutral." Efficacy averaged $3.5(\mathrm{SD}=.58)$.

Lastly, question 21 allowed participants to describe in more detail about their EAP. The responses were coded into three themes: Other Provider/Contact, Groups/Workshops, and Obligation. Twenty-five percent (25\%) mentioned that they had an obligation as employees to remain mindful of their well-being, and $25 \%$ also contracted the EAP through someone else, whether it was a company or a specific contact. Fifty percent (50\%) said a group or a workshop was incorporated into the EAP.

Similar to the reasoning for question 11, the amount of research about EAPs and museums is almost non-existent and was asked to create a baseline within the literature. More organizations indicated that they had an EAP than a business continuity plan, where history and children's museums were the top two categories for having such policies/documents.

These questions were asked to get a better insight on those who answered that their institution did have an EAP. According to the study conducted by Richmond et al. [6], the majority of businesses indicated that they used their EAP in correlation with a disaster and incorporated the EAP as such. The data from this study contradicts Richmond et al. slightly, where all respondents said that their EAP was located in a Human Resource document. However, the second highest response in the study by Richmond et al. was "organizational development of EAP," and the results from this study correlates more with that response.

Participants who answered questions 16 through 18 indicated that their institution did not have an EAP and the questions were structured to gain a better understanding as to why they 
did not have one. Question 16 was asked to create a foundation in the literature as to why museums do not have EAPs. Like question 14, question 17 sought to gain a better understanding as to the location of an EAP document.

These responses echoed more closely to the study by Richmond et al, than respondents who answered that they had an EAP. Forty-two percent (42\%) of respondents said the EAP would most likely be in the disaster plan, $36 \%$ believed it was in a different location such as an employee handbook, and $21 \%$ thought it would be in the business continuity plan. This is compared to the results from Richmond et al. where $61 \%$ said disaster planning, $36 \%$ said integrated policy/procedure support, and $25 \%$ said continuity plans.

Question 18 sought out to measure the amount of interest in developing an EAP for those institutions that did not have one. History and art museums were more receptive of developing an EAP than children's and nature/science museums.

Questions 19 through 21 were answered by participants who indicated that they implemented their EAP. Questions 19 and 21 provided no significant findings relevant to the research goals.

However, question 20 did provide enough data to establish a baseline in the literature. Half of the institutions sampled expressed EAP efficacy to be "Neutral" and the other half as "Great."

\section{CONCLUSION}

The purpose of this study was to evaluate how museums help their employees return to workplace normalcy after a natural disaster impacts their institution and address what policies museums use to facilitate this transition. The results show that museums have disaster preparedness plans but do not have business continuity plans or EAPs, and that museums are not utilizing these documents to help employees return to workplace normalcy should a natural disaster impact their institution.

\subsection{Limitations}

A sample size of 80 is a small representation of the museum community in major urban cities in California. Additionally, this study focuses on California museums and the major natural hazards they identify in their disaster planning may not be indicative of the rest of the United States. Furthermore, this study focused on natural disasters and did not include man-made or technological disasters.

Data size was limited because it was difficult to obtain documents for a potential document analysis because of the nature of the study. Follow-up emails to most respondents indicated they were not comfortable sharing this information.

\subsection{Recommendations}

Since museum disaster plans are a well-established and researched topic in the field, they can provide the foundation to incorporate business continuity plans and EAPs as part of a comprehensive disaster document. Business continuity plans have great overlap with the disaster plan recovery stage. Furthermore, because recent literature in business continuity plans address human capital and resiliency, it offers an avenue to incorporate an EAP. Even though EAP research is still developing, museums can look to EAPs as a way to help facilitate employees back into workplace normalcy. Moreover, further research in this field could lead to a design and implementation of an in-house EAP for smaller staff sizes. 


\section{REFERENCES}

[1] American Alliance of Museums, Core documents, http://www.aamus.org/resources/assessment-programs/core-documents/document. Accessed on: 15 Nov. 2015.

[2] International Council of Museums, Standards \& guidelines. http://icom.museum/professional-standards/standards-guidelines/. Accessed on: 15 Nov. 2015.

[3] Dorge, V. \& Jones, S.L., Building an Emergency Plan: A Guide for Museums and Other Cultural Institutions, Getty Conservation Institute: Los Angeles, CA, p. 85, 1999.

[4] Doughty, K., Business Continuity Planning: Protecting Your Organization's Life, CRC Press LLC: Danvers, MA, p. 9, 2001.

[5] Stephenson, D. \& Schneider, D.U., Case studies of federal occupational health's EAP responses to natural disasters. Journal of Workplace Behavioral Health, 21(3-4), p. 9, 2006. DOI: $10.1300 / \mathrm{J} 490 \mathrm{v} 21 \mathrm{n} 0303$.

[6] Richmond, M.K., Pampel, F.C., Wood, R.C. \& Nunes, A.P., The impact of employee assistance services on workplace outcomes: Results of a prospective, quasi-experimental study. Journal of Occupational Health Psychology, p. 7, 2015. DOI: $10.1037 /$ ocp0000018.

[7] Layne, S.P., Safeguarding Cultural Properties: Security for Museums, Libraries, Parks and Zoos, Elsevier Inc.: Oxford, UK, p. xiii, 2014.

[8] United States Department of Homeland Security (DHS), Natural disasters. https://www.ready.gov/natural-disasters. Accessed on: 9 Dec. 2015.

[9] United States Federal Emergency Management Agency (FEMA), FEMA disaster declarations summary - open government dataset. http://www.fema.gov/medialibrary/assets/documents/28318. Accessed on: 9 Dec. 2015.

[10] Matteson, M.T. \& Ivancevich, J.M., Controlling Work Stress: Effective Human Resource and Management Strategies, Jossey-Bass Inc.: San Francisco, CA, p. 275, 1987. 